\title{
Development of micro rotary swaging tools of graded tool steel via co-spray forming
}

\author{
Chengsong Cui ${ }^{1, \mathrm{a}}$, Alwin Schulz ${ }^{1}$, Eric Moumi ${ }^{2}$, Bernd Kuhfuss ${ }^{2}$, Florian Böhmermann ${ }^{3}$, \\ and Oltmann Riemer ${ }^{3}$ \\ ${ }^{1}$ Foundation Institute for Materials Science, Badgasteiner Str. 3, 28359 Bremen, Germany \\ ${ }^{2}$ Bremen Institute for Mechanical Engineering, University of Bremen, Badgasteiner Str. 1, \\ 28359 Bremen, Germany \\ ${ }^{3}$ Laboratory for Precision Machining (LFM), University of Bremen, Badgasteiner Str. 2, \\ 28359 Bremen, Germany
}

\begin{abstract}
In order to meet the requirements of micro rotary swaging, the local properties of the tools should be adjusted properly with respect to abrasive and adhesive wear, compressive strength, and toughness. These properties can be optimally combined by using different materials in specific regions of the tools, with a gradual transition in between to reduce critical stresses at the interface during heat treatment and in the rotary swaging process. In this study, a newly developed co-spray forming process was used to produce graded tool materials in the form of a flat product. The graded deposits were subsequently hot rolled and heat treated to achieve an optimal microstructure and advanced properties. Micro plunge rotary swaging tools with fine geometrical structures were machined from the hot rolled materials. The new forming tools were successfully applied in the micro plunge rotary swaging of wires of stainless steel.
\end{abstract}

\section{Introduction}

The selection of tool materials for micro rotary swaging processes is an important issue. As the tools are loaded differently in different functional areas adapted material properties are required. For example, the tool surface should be hard and resistant to wear and the tool body should have sufficient toughness $[1,2]$. The varying properties can be optimally combined by using different materials in the specific regions of the tools. The combination of materials can be achieved by the use of a gradual transition in between to reduce critical stresses at the interface during heat treatment and in the swaging process. Such graded materials have much lower tendency to delaminate than surface-coated materials.

On the other hand, tool materials for micro rotary swaging should be precisely machinable by micromachining because the required geometrical structures of the tool surfaces are significantly smaller than $1 \mathrm{~mm}$ in more than one dimension [2]. To meet this requirement, the tool materials should exhibit fine

\footnotetext{
${ }^{\text {a }}$ Corresponding author: cscui@iwt.uni-bremen.de
}

This is an Open Access article distributed under the terms of the Creative Commons Attribution License 4.0, which permits unrestricted use, distribution, and reproduction in any medium, provided the original work is properly cited. 


\section{MATEC Web of Conferences}

and homogenous microstructure since the precision machining of the tool structures may be interfered by large carbides or significant segregation [3].

A newly developed co-spray forming process is supposed to produce such graded tool materials [4]. In this process, two melts of different tool steels are co-sprayed and deposited on a flat substrate, resulting in a graded flat product when the two sprays partially overlap. By means of combining two tool steels in a single deposit, different microstructure and properties can be combined [5, 6]. In addition, a fine and homogeneous microstructure can be achieved in the spray-formed materials due to rapid solidification [7, 8]. In this study, flat deposits of graded tool steel (HS6-5-3C / X110CrMoV8-2) were produced by this novel co-spray forming process. The graded deposits were subsequently hot rolled and heat treated to achieve optimal microstructure and material properties. Micro plunge rotary swaging tools were machined from the graded steels and tested in the deformation of wires of stainless steel 1.4301 (AISI 304).

\section{Production of tool materials}

A high speed steel HS6-5-3C (AISI M3:2) was applied in the tool surface area and a cold working steel X110CrMoV8-2 was applied in the tool body. A large number of carbides in HS6-5-3C are responsible for high hardness and excellent wear resistance. X110CrMoV8-2 shows significantly higher toughness compared to the high speed steel. The co-spray forming of the graded steel was carried out on the spray forming facility SK1+ at the University of Bremen and shown in Fig. 1(a). The steels were melted in separate crucibles, and atomized by means of nitrogen gas jets generated by two free-fall gas atomizers. A flat ceramic substrate was used to collect the atomized droplets. HS6-5-3C was first spray-deposited on the substrate to form the lower layer of the deposit, followed by the deposition of X110CrMoV8-2 and the forming of the upper layer of the deposit. Since the two spray cones overlapped partially, a gradient zone was generated between the two layers. The superheating temperature of both melts was $180^{\circ} \mathrm{C}$. The pouring nozzle diameter was $4.5 \mathrm{~mm}$ for HS6-5-3C and $6.5 \mathrm{~mm}$ for X110CrMoV8-2. The melt mass flow rates were $0.22 \mathrm{~kg} / \mathrm{s}$ and $0.47 \mathrm{~kg} / \mathrm{s}$, respectively. The gas atomizers scanned in the transverse direction of the substrate. The scanning angle of the atomizers was kept at $10.5^{\circ}$, and the scanning frequency at $5 \mathrm{~Hz}$. The atomization gas pressure was $0.2 \mathrm{MPa}$ for the HS6-5-3C melt and $0.5 \mathrm{MPa}$ for the X110CrMoV8-2 melt, corresponding to a gas mass flow rate of $0.17 \mathrm{~kg} / \mathrm{s}$ and $0.33 \mathrm{~kg} / \mathrm{s}$, respectively. The substrate was preheated to $600{ }^{\circ} \mathrm{C}$ and moved at a translational speed of $6 \mathrm{~mm} / \mathrm{s}$. The vertical spray distance from the atomizers to the substrate was $580 \mathrm{~mm}$. The central distance between the atomizers was $340 \mathrm{~mm}$. A distance of $218 \mathrm{~mm}$ or $156 \mathrm{~mm}$ between the axes of the two sprays at the substrate surface was determined as the tilting angles of both atomizers were $6^{\circ}$ or $9^{\circ}$. The spray-formed deposits were in the form of a flat product, with the dimensions of $250 \mathrm{~mm}$ width, $500-600 \mathrm{~mm}$ length, and 55-60 mm thickness.

The spray-formed deposits were soft annealed to reduce hardness and avoid cracking. They were heated to $840{ }^{\circ} \mathrm{C}$ at the rate of $50 \mathrm{~K} / \mathrm{h}$ and hold for $4 \mathrm{~h}$, followed by cooling to $500^{\circ} \mathrm{C}$ at the rate of $20 \mathrm{~K} / \mathrm{h}$ and then cooling in furnace.

The spray-formed graded deposits were subsequently hot rolled on a lab rolling mill at the University of Bremen to eliminate porosity and break up the carbide network. Rolling samples with a thickness of 44-49 mm, a width of $32 \mathrm{~mm}$ and a length of $200 \mathrm{~mm}$ were machined from the graded deposits. The samples were preheated in a furnace to $1100{ }^{\circ} \mathrm{C}$ and rolled in three passes to a final thickness of approximately $24 \mathrm{~mm}$. For each rolling pass, the true strain and the strain rate of the sample were about $0.2-0.3$ and $1 \mathrm{~s}^{-1}$, respectively. The total strain of the sample was 0.6-0.7.

Microscopic samples and semi-finished tools were machined from the hot rolled materials. They were hardened and tempered prior to final grinding or milling. They were austenitized in a vacuum furnace at $1080^{\circ} \mathrm{C}$ for $20 \mathrm{~min}$, followed by gas quenching with 6 bar nitrogen. Subsequently, the samples 


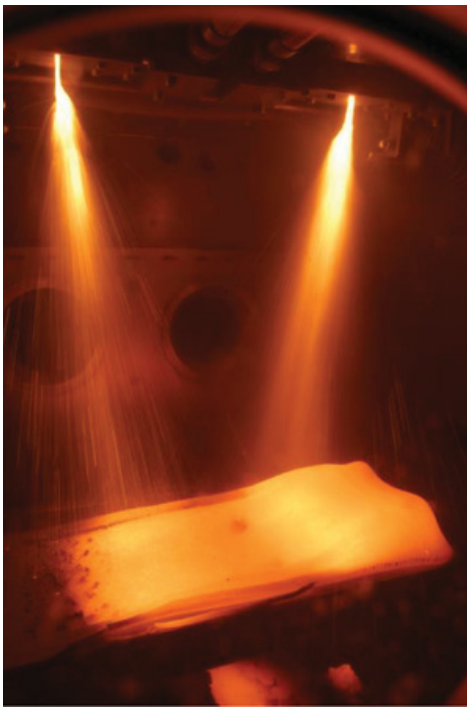

(a)

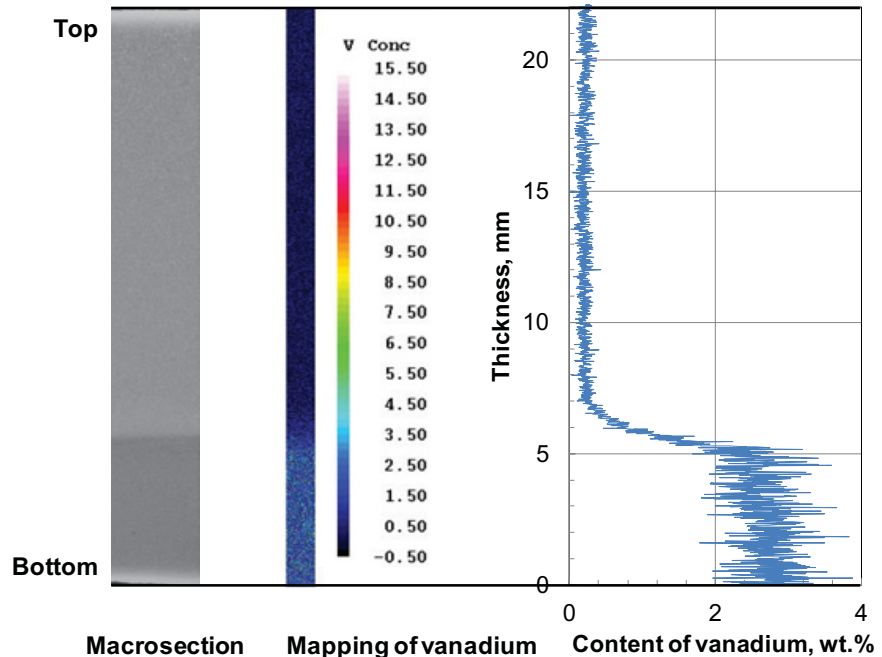

(b)

Figure 1. (a) Co-spray forming of a graded steel deposit (X110CrMoV8-2/HS6-5-3C, tilting angle of atomizer $6^{\circ}$ ) and (b) element distribution of the graded steel (after hot rolling).

were tempered three times at $550^{\circ} \mathrm{C}$ for $2 \mathrm{~h}$ and cooled in air. The hardness of the X110CrMoV8-2 was about 65 HRC and about 66 HRC for the HS6-5-3C.

The distributions of the main chemical elements in the hot rolled materials were analyzed by means of electron probe microanalysis (model: JEOL JXA-8200). A typical element distribution (vanadium) across the thickness of the hot rolled steels is shown in Fig. 1(b). The curve was obtained by calculating the mean values of the element content from the mapping of the element. A picture of the macroetched sample is combined with the element curve in the figure. The material of the upper part is $\mathrm{X} 110 \mathrm{CrMoV} 8-2(0.5 \mathrm{wt} . \% \mathrm{~V})$, and the material of the lower part is HS6-5-3C (3 wt.\% V). The gradient zone is in the range of $5-7 \mathrm{~mm}$ from the base of the hot rolled sample.

The representative microstructure of the hot rolled steels (after hardening and tempering) is shown in Fig. 2 (optical microscopy, Model: Axiophot, ZEISS). The etchant Nital was used to reveal the microstructure of the samples. The porosity commonly existing in the graded deposits was essentially eliminated by the hot rolling. The hot rolled materials show a relatively fine and homogeneous microstructure. The carbide network of the deposits was also broken up to some extent due to hot working. There are remarkably more and larger carbides in the lower layer (HS6-5-3C) than in the upper layer (X110CrMoV8-2) of the graded steels. A gradual transition of the microstructure is obviously seen in the graded steels.

\section{Machining of micro rotary swaging tools}

Two sets of micro plunge rotary swaging tools, for deforming wires to a diameter of $0.5 \mathrm{~mm}$ and $0.8 \mathrm{~mm}$ respectively, were manufactured by micro milling. The tool surface consisted of HS6-5-3C, the tool body of X110CrMoV8-2, with the gradient zone in between (see Fig. 3). The machining was carried out on a DMG Sauer Ultrasonic 20 linear machine tool. The machining operation comprised multiple, consecutive roughing and finishing steps. CAD/CAM-programming was used for tool path generation. Hard coated tungsten carbide ball-end mills of $1.0 \mathrm{~mm}$ for roughing and $0.5 \mathrm{~mm}$ diameter for finishing 


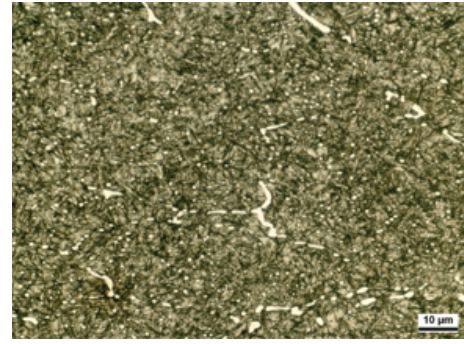

(a)

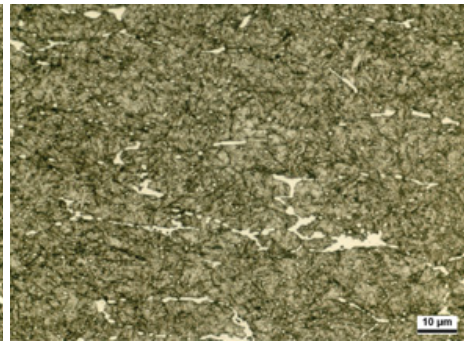

(b)

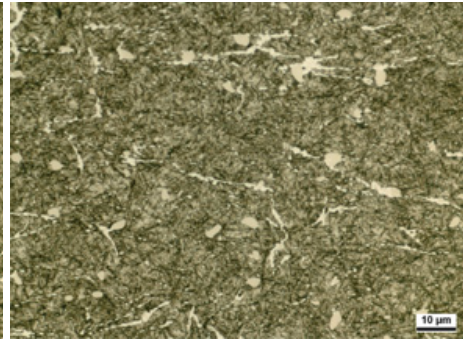

(c)

Figure 2. Microstructure of the graded tool steel processed by co-spray forming, hot rolling, hardening and tempering: (a) X110CrMoV8-2; (b) X110CrMoV8-2+HS6-5-3C; and (c) HS6-5-3C.

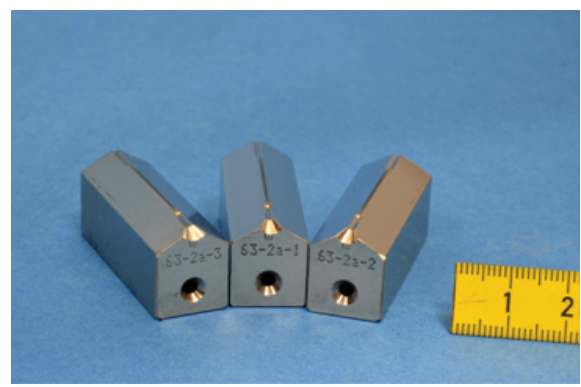

(a)

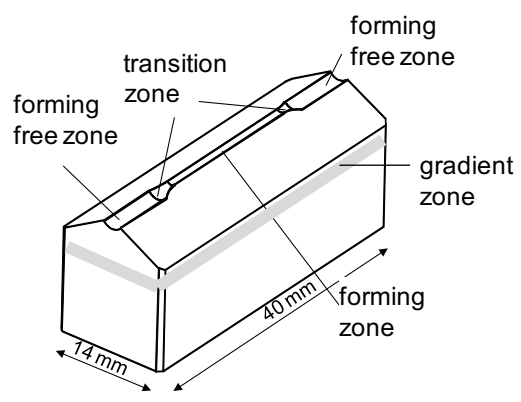

(b)

Figure 3. Micro plunge rotary swaging tools of graded tool steel (X110CrMoV8-2/HS6-5-3C): (a) set of swaging tools; and (b) micro swaging tool with indicated different functional areas.

were applied. Material allowance for the finishing cut was $10 \mu \mathrm{m}$. The depth of cut and the width of cut for finishing were set to $\mathrm{a}_{\mathrm{p}}=5 \mu \mathrm{m}$ and $\mathrm{a}_{\mathrm{e}}=5 \mu \mathrm{m}$, respectively. The spindle speed and the feed velocity were kept constant at $\mathrm{n}=40,000 \mathrm{~min}^{-1}$ and $\mathrm{v}_{\mathrm{f}}=1,000 \mathrm{~mm} / \mathrm{min}$.

\section{Micro rotary swaging of steel wires}

Rotary swaging is an incremental forming process for tubes, bars and wires. Forming takes place in the rotary swaging head (Fig. 4a) by quick oscillating movement of the forming tools (1). Due to the rotation of the driven shaft (4) when the base jaws come across a cylinder roller (3) the forming tools are pushed inwards and the workpiece (5) is deformed [9].

There are two main variations of the process: the infeed rotary swaging during which the diameter of the workpiece is reduced over the complete feed length, and the plunge rotary swaging which allows local diameter reductions. In this study, the plunge rotary swaging was applied and Fig. 4b shows the principle of this variation. In plunge rotary swaging, additionally to the oscillating movement, the forming tools achieve a radial displacement towards the workpiece due to the axial displacement of the wedges.

The graded tools were applied in a rotary swaging machine (Type Felss HE 3/DE) to reduce the diameter of wires of stainless steel 1.4301 (AISI 304). For the first set of forming tools $(\varnothing 0.5 \mathrm{~mm}$ forming zone), the wires were in pre-strained state (surface hardness $430 \mathrm{HV} 0.1$ ) with an initial diameter of $\mathrm{d}_{0}=0.7 \mathrm{~mm}$ and were reduced in one step to the final diameter of $\mathrm{d}_{1}=0.5 \mathrm{~mm}$, corresponding to a 

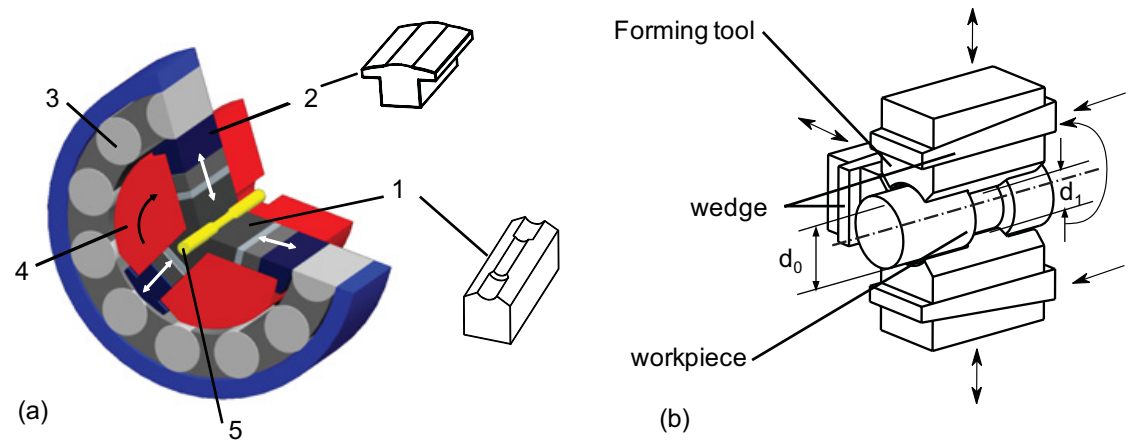

(b)

Figure 4. (a) Assembly of rotary swaging head and (b) principle of plunge rotary swaging.

Transition zone

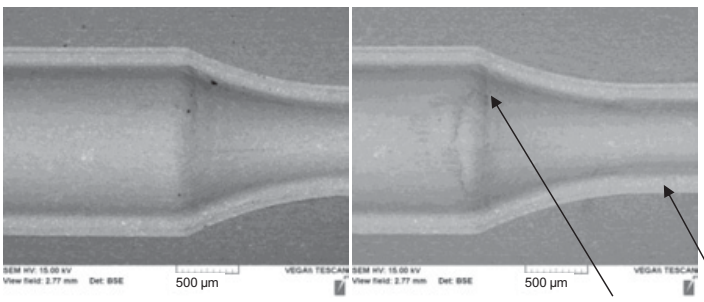

Adhesive wear

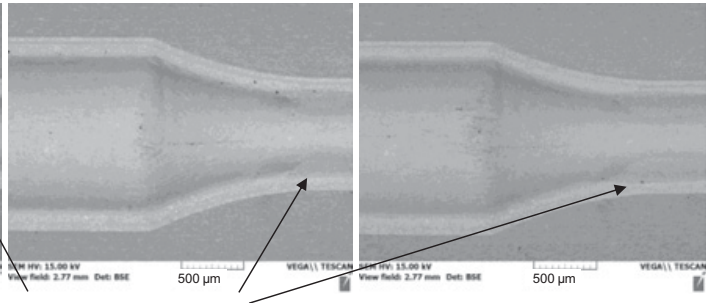

Edge deformation

Forming zone

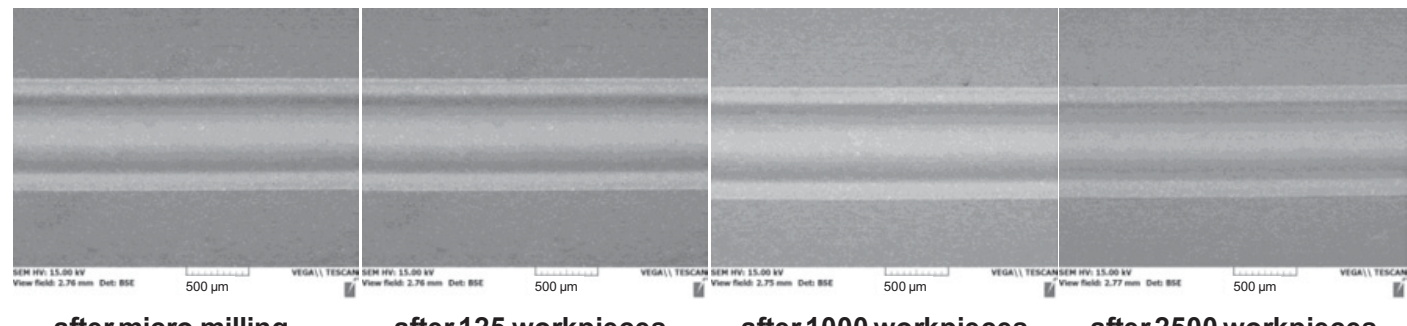

after micro milling

after 125 workpieces

after 1000 workpieces

after 2500 workpieces

Figure 5. Tool surfaces of the micro plunge rotary swaging tools (forming zone $\varnothing 0.8 \mathrm{~mm}$ ).

strain of 0.67 . For the second set of forming tools ( $\varnothing 0.8 \mathrm{~mm}$ forming zone), the wires were in a soft annealed state (surface hardness $300 \mathrm{HV0.1}$ ) with an initial diameter of $1.0 \mathrm{~mm}$, corresponding to a strain of 0.45 . The tool oscillated with a frequency of $100 \mathrm{~Hz}$ and the radial displacement was set to $35 \mu \mathrm{m} / \mathrm{s}$. The gradient zone between the two steels (X110CrMoV8-2/HS6-5-3C) did not show signs of fracture or cracking after the test (up to 2500 pieces).

The tool surfaces and the steel wires before and after the rotary swaging were investigated by means of scanning electron microscope (model: CAMSCAN CS44, Elektronen-Optik-Service GmbH). Stereoscopic images were used to retrieve 3D information of the tool surfaces (using MeX software from Alicona). It showed that the tool surfaces were smooth and the fine geometrical structures of the tool were precisely machined by micro milling. Only slight traces of micro milling were observed at the tool surfaces. The excellent micro-machinability of the graded steel was guaranteed due to its relatively fine and homogeneous microstructure.

The transition zone of the first set of tools was seriously deformed after swaging of 2500 pieces of AISI 304 wire (from $\varnothing 0.7 \mathrm{~mm}$ to $\varnothing 0.5 \mathrm{~mm}$ ). However, the forming zone was not changed. It is surprising 


\section{MATEC Web of Conferences}
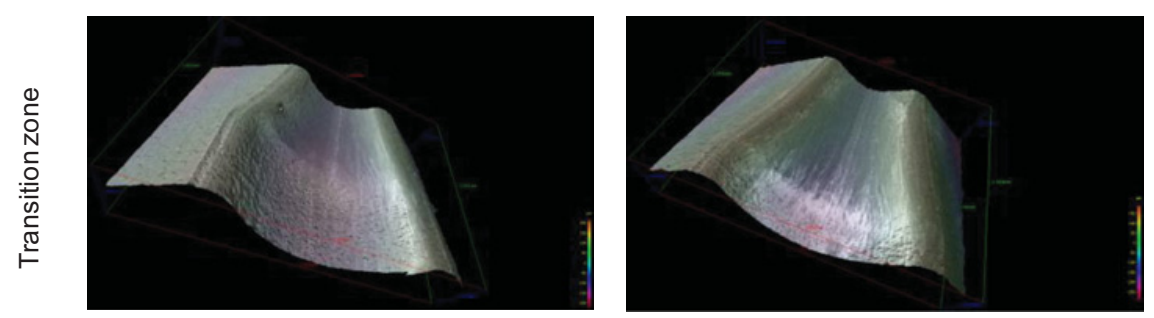

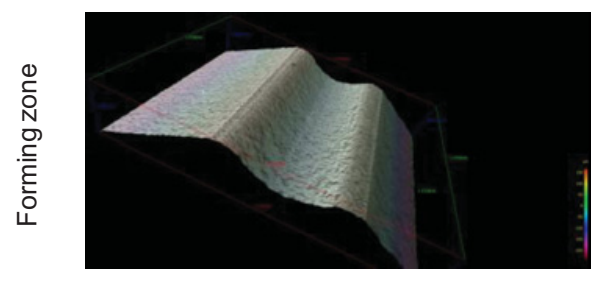

after micro milling

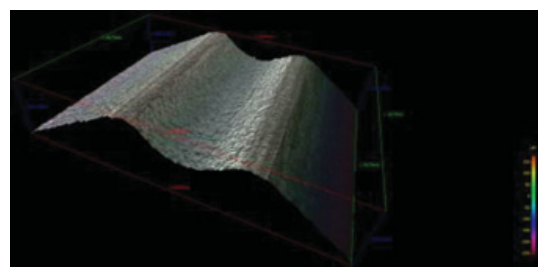

after 2500 workpieces

Figure 6. Topography of the tool surfaces after micro milling and after micro plunge rotary swaging.

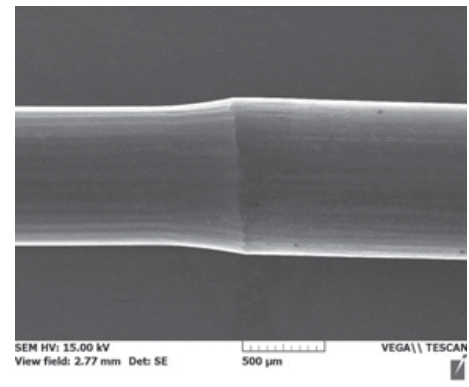

(a) workpiece no. 125

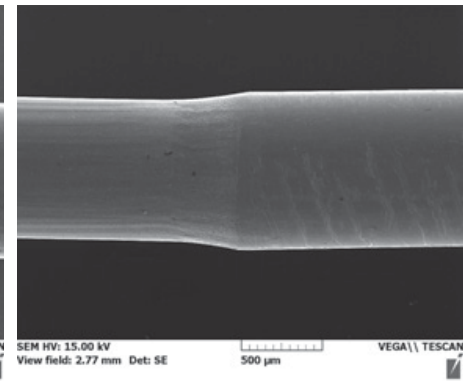

(b) workpiece no. 1000

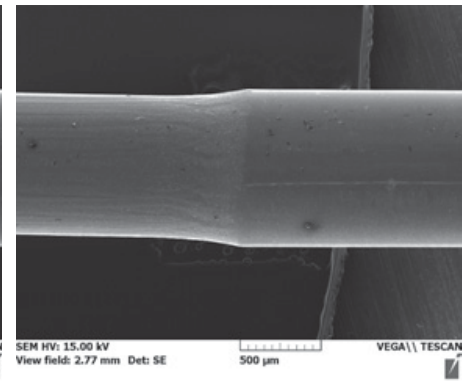

(c) workpiece no. 2500

Figure 7. AISI 304 steel wires deformed from $\varnothing 1 \mathrm{~mm}$ to $\varnothing 0.8 \mathrm{~mm}$ by micro plunge rotary swaging.

that the deformation of the tool surface occurred in the transition zone but not in the forming zone, since the load (impact force during swaging) was higher in the forming zone than in the transition zone. Further investigation will be carried out to interpret this tool damage in the near future. In this paper, the evaluation of the tool performance is focused on the second set of tools.

The tool surfaces of the second set of micro plunge rotary swaging tool are shown in Fig. 5 and Fig. 6. This tool set had a larger forming zone $(\varnothing 0.8 \mathrm{~mm})$. The steel wire was deformed from $1 \mathrm{~mm}$ to $0.8 \mathrm{~mm}$ with a strain of 0.45 , lower than that for the first tool set. The wire used was also softer (300 HV0.1). By comparing the tool surfaces before and after micro rotary swaging, it is seen that severe plastic deformation in the transition zone was avoided, although slight adhesion of the workpiece on the tool surfaces and slight deformation at the entrance of the forming zone appeared. It indicates that a small deformation ratio and soft workspieces lead to lower loads on the tool surfaces and reduce damage of the forming tools. It is believed that the lifetime of the tools can be extended by using stronger tool steels with more carbide at the tool surfaces. The steel wires deformed by the second set of swaging tools are shown in Fig. 7. The shape, size and surface quality of the deformed wires are satisfactory. 


\section{ICNFT 2015}

\section{Summary}

The graded steel (X110CrMoV8-2/HS6-5-3C) was produced by means of co-spray forming and hot rolling, showing a relatively fine and homogeneous microstructure. After hardening and tempering, the hardness of the steels X110CrMoV8-2 and HS6-5-3C was about 65 HRC and 66 HRC, respectively. The graded steel could be machined precisely to micro plunge rotary swaging tools with smooth tool surfaces and fine geometrical structures. Damage of the tools could be prevented by reducing the deformation ratio and the strength of the workpieces. The deformed wires showed satisfactory shape, size and surface quality.

The authors gratefully acknowledge the financial support by Deutsche Forschungsgemeinschaft (DFG, German Research Foundation) for the Subprojects A4, C2, and C6 within the SFB 747 (Collaborative Research Center) "Mikrokaltumformen - Prozesse, Charakterisierung, Optimierung".

\section{References}

[1] A. Schulz, Tool Materials, In Micro Metal Forming (Springer-Verlag, Berlin, 2013)

[2] F. Vollertsen, H. Schulze Niehoff, Z. Hu, Inter. J. Mach. Tool Manu. 46, 1172 (2006)

[3] H. Flosky, F. Vollertsen, Key Eng. Mater. 549, 511 (2013)

[4] C. Cui, A. Schulz, Metall. Mater. Trans. 44B, 1030 (2013)

[5] C. Cui, A. Schulz, V. Uhlenwinkel, Steel Res. Int. 84, 1075 (2013)

[6] C. Cui, A. Schulz, V. Uhlenwinkel, Mater. Sci. Eng. Technol. 45, 652 (2014)

[7] U. Fritsching, Spray Simulation - Modelling and Numerical Simulation of Sprayforming Metals, (Cambridge University Press, Cambridge, 2004)

[8] E.J. Lavernia, Y. Wu, Spray Atomization and Deposition (John Wiley, New York, 1996)

[9] B. Kuhfuß, E. Moumi, V. Piwek, Microsystem. Technol. 14, 1995 (2008) 